[CONTRIBUTION FROM THE KENT ChEMICAL LABORATORY OF THE UNIVERSITY OF Chicago.]

\title{
A CONTINUOUS-READING ELECTROTITRATION APPARATUS.
}

\section{BY KeNNETH H. GOODE.}

Received August 22, 1921.

The simplest possible apparatus for electrometric titration, from a theoretical standpoint, would be a sensitive voltmeter connected between a calomel electrode and a hydrogen electrode. In practice, however, an

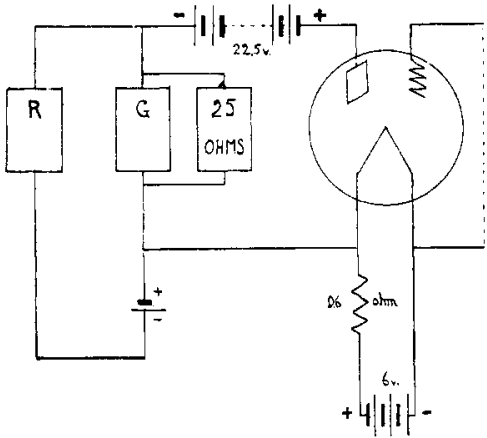
ordinary voltmeter cannot be used, because the instrument would consume current enough from the cell to discharge the hydrogen electrode, and render it inoperative. For this reason all types of apparatus hitherto in use have depended upon balancing the unknown e.m.f. of the cell being used against a variable known e.m.f. produced by a potentiometer system, the balance being determined by a "null-point" galvanoFig. 1,-Diagram of original circuit. meter. With this type of apparatus a balance of potentials must be made before each reading of the voltage, and there is considerable uncertainty in the readings when the potential of the cell is rapidly changing. The investigation described in this paper has shown that the 3 -electrode vacuum valve ("audion") presents almost the ideal case of a "voltmeter" which draws no current from the source to be measured, and can therefore be employed as a continuous-reading instrument for determining the concentration of the hydrogen ion.

The 3-electrode valve consists of a highly exhausted glass bulb containing an incandescent filament surrounded by a grid of fine wire, which is itself surrounded by a metallic plate. A high voltage battery of 20 to 100 volts connected between the plate and the filament produces a current through the "plate circuit," whose magnitude is a function of the potential of the grid. This plate current, $\left(I_{p}\right)$, may be considered as the sum of a constant current, $\left(I_{0}\right)$, which is independent of the grid potential, and a current $\left(I_{p}-I_{0}\right)$ which is nearly a linear function of the grid potential. In order to measure $\left(I_{p}-I_{0}\right)$ it was found necessary to balance the

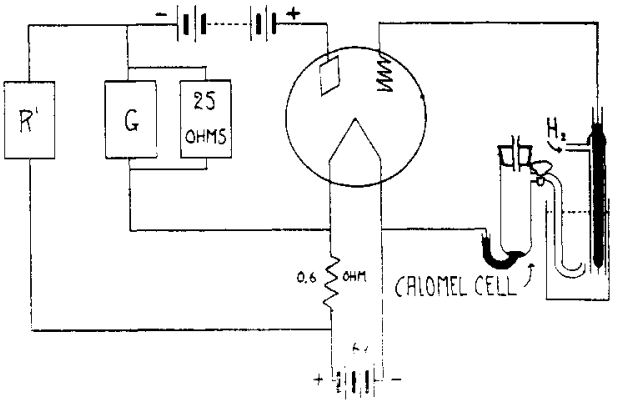

Fig. 2,-Diagram of improved circuit. 
current $I_{0}$ with an equal current in the opposite direction. The remaining current is measured with a galvanometer or micro-ammeter, which may be calibrated to read directly in volts, or in Sörensen units $\left(P_{\mathrm{H}}\right)$. With the proper connections, the current in the grid circuit, through the titration cell, is negligible, so that no circuit-breaking key is required, and the current $\left(I_{p}-I_{0}\right)$ indicates at each moment the potential of the hydrogen electrode.

The vactum tube used was a "Radiotron," type UV 201, which was lighted by means of a 6-volt storage battery. The filament current was adjusted at 1.06 amperes by the introduction of a resistance of about 0.6 ohms. Under these conditions the potential of the battery was 6.1 volts, while that across the terminals of the resistance was 0.6 volts. The plate battery was a 22.5-volt unit, giving a steady plate current $\left(I_{0}\right)$ of 0.00045 amperes. It

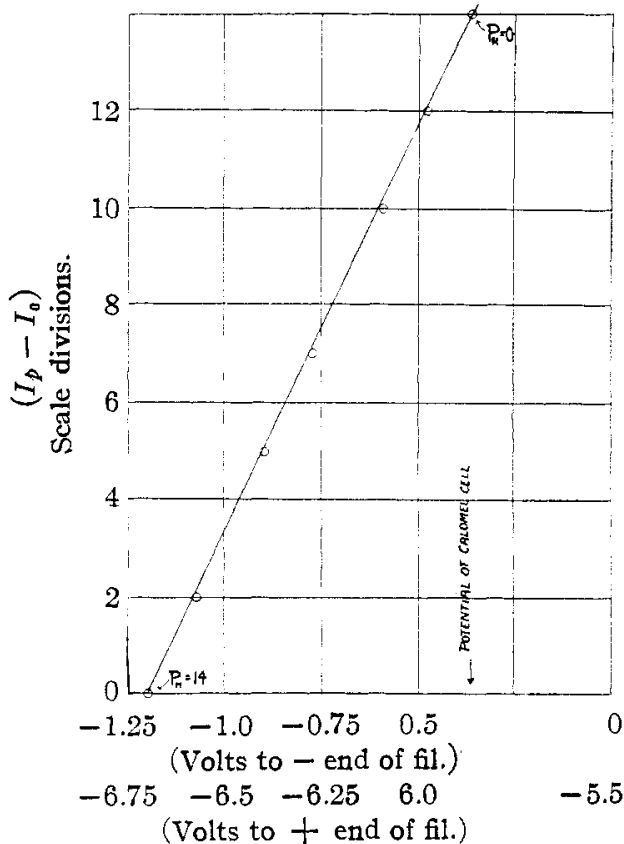

Fig. 3.-Variation of $\left(I_{p}-I_{0}\right)$ with potential of grid. was at first thought that this steady current could be balanced by the torsion of the galvanometer suspension, but this was found impracticable because of a steady shift of the zero point. It was found possible, however, to balance the steady current by an equal and opposite current produced by a dry-cell acting through about $3000 \mathrm{ohms}$ or resistance, $R$ (Fig. 1). The circuits were later simplified, and a more steady zero point obtained by replacing this battery by the potential difference at the terminals

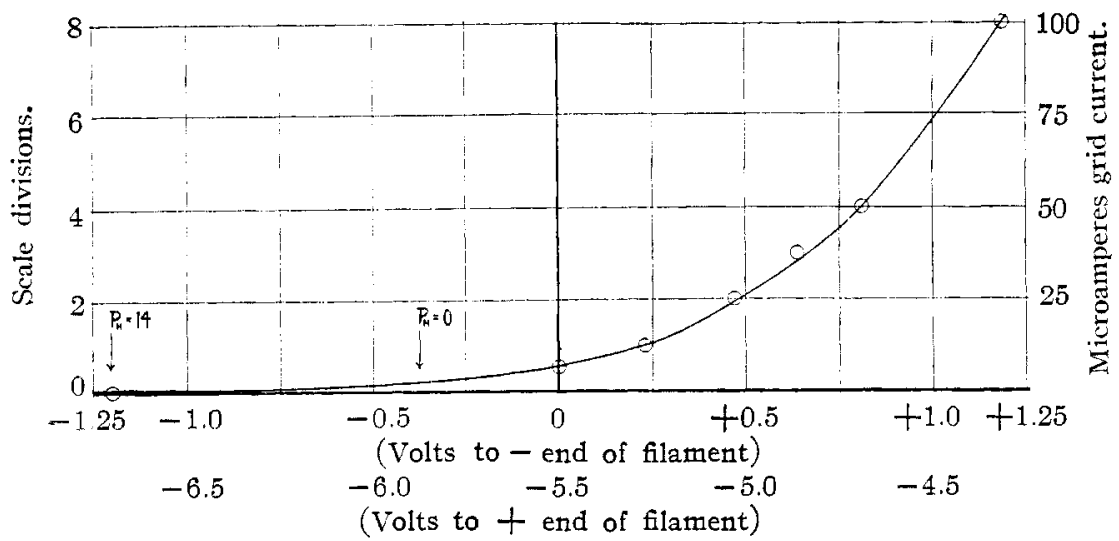

Fig. 4.-Effect of potential on grid current. 
of the filament resistance, acting through an adjustable resistance, $R^{\prime}$, of about 1300 ohms (Fig. 2).

In order to obtain a steady zero point, the filament current must be maintained at a constant value, which is passible only by protecting the

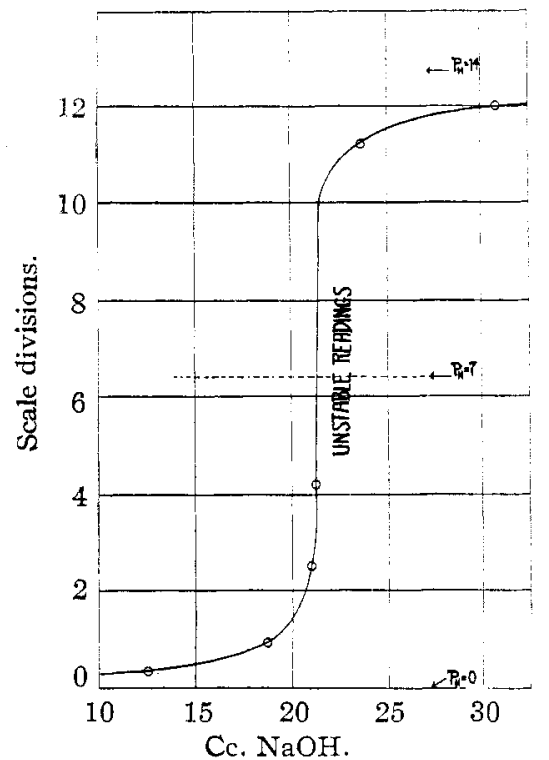

Fig. 5.-Titration of $\mathrm{HCl}$.

of $I_{p}-I_{0}$ in scale divisions. Although necessarily situated on a curve, the points lie within $1 \%$ of the straight line, representing a linear relation between $I_{p}-I_{0}$ and the corresponding Sörensen value.

The current in the grid circuit of an audion depends upon the potential of the grid, measured with respect to the positive terminal of the filament; and at potentials near zero, $(i . e$., with the titration cell connected between the grid and the positive end of the filament), the current is so great filament resistance and its connecting wires from slight changes of temperature. With this precaution a perfectly steady and reliable zero point is assured.

For measuring the current, $I_{p}-I_{0}$, a D'Arsonval galvanometer, G (Figs. 1 and 2 ), having a sensitivity of $0.62 \times 10^{-6}$ amperes per scale division $^{1}$ was employed. By using a shunt of 25 ohms, the sensitivity was reduced to $10.1 \times 10^{-6}$ amperes per scale division, which corresponded very closely to one Sörensen unit $\left(P_{\mathrm{H}}\right)$ for each scale division under the conditions in which it was finally used. Fig. 3 shows the calibration curve under these conditions, the abscissas being the potentials of the grid in volts, and the ordinates the values

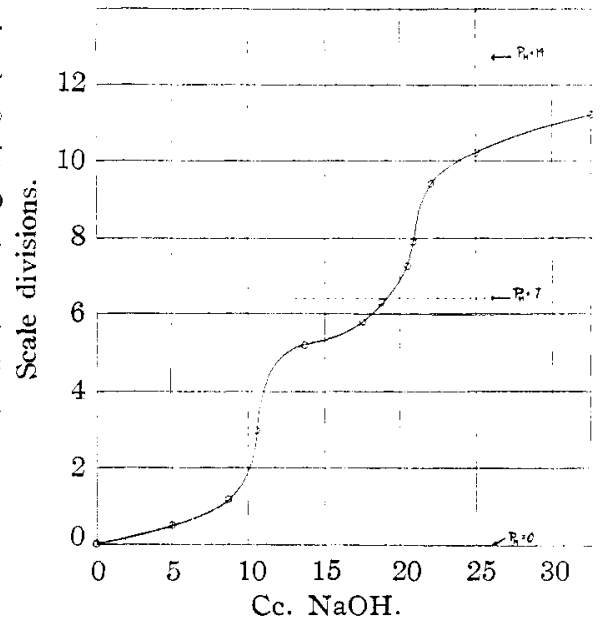

Fig. 6.-Titration of $\mathrm{H}_{3} \mathrm{PO}_{4}$.

1 Deflections were observed by means of a telescope and scale, both located about $40 \mathrm{~cm}$. from the galvanometer mirror, the scale divisions being each $1 \mathrm{~cm}$. in length. The apparent angular displacement of the scale per micro-ampere, with the 25-ohm shunt, would then be $0^{\circ} 8^{\prime} 36^{\prime \prime}$, or 0.0025 radians. 
as to discharge the hydrogen electrode immediately. When the grid is given a negative potential, however, the current decreases, becoming zero at about -7 volts. Fig. 4 indicates this effect, the ordinates being in this case scale divisions of a "Cenco" null-point galvanometer (1 scale division $=12 \times 10^{-6}$ amps.), while the abscissas are, as before, the potential of the grid in volts. Potentials near -5.5 volts are conveniently obtained by connecting the titration cell between the grid and the negative end of the filament. By connecting the hydrogen electrode to the grid and the calomel electrode to the filament, potentials between -5.8 and -6.7 volts are obtained, within which range the grid current is entirely negligible.

Typical titration curves obtained with this arrangement are shown in Figs. 5 and 6 . In these cases, and for all titrations, the terminals of the galvanometer were reversed and the resistance $\mathrm{R}^{\prime}$ adjusted at such a value that the scale-reading was zero when the Sörensen value was zero. By a careful adjustment of the shunt resistance, the scale divisions will now directly indicate the Sörensen values in the titration cell. ${ }^{2}$ Some difficulty was experienced in getting constant readings in regions of the curves where the Sörensen value changes abruptly, because the stirring necessary to produce a homogeneous solution resulted in a momentary decrease in the potential of the hydrogen electrode of about 0.02 volts. For this reason it was found necessary to stop stirring about 2 seconds before each reading was taken. With a constant stirring apparatus it might be possible to allow for this effect.

The sensitivity of the apparatus described in this paper is of the order of 0.1 Sörensen unit, or 0.006 volts. By merely employing a galvanometer scale capable of being read to 0.01 scale division (defined as before), the sensitivity might be increased tenfold, but unless the effect of stirring mentioned above is nullified, further improvement in this direction would seem useless.

The writer wishes to express his appreciation of the advice of Dr. Gerald L. Wendt in connection with this work.

Chicago, Illinors.

${ }^{2}$ In the titrations of Figs. 5 and 6 , however, adjustment could only be made to the nearest ohm (25 ohms), and 14 Sörensen units are here represented by 12.8 scale divisions. 